\title{
HIV infection and AIDS in the European Union and European Economic Area, 2010
}

G Likatavicius (giedrius.likatavicius@ecdc.europa.eu)1, M J van de Laar ${ }^{1}$

1. European Centre for Disease Prevention and Control (ECDC), Stockholm, Sweden

In 2010, a total of 27,116 newly diagnosed HIV infections were reported by 28 countries of the European Union and European Economic Area (EU/EEA), with evidence of continuing transmission and no clear signs of decline. The predominant mode of transmission and increasing trend of HIV in the EU/EEA was due to sex between men. An increase in AIDS diagnoses in several countries and a high proportion of late presenters suggest delayed access to treatment and care.

\section{Newly diagnosed HIV infections}

In the European Union and European Economic Area (EU/EEA), 27,116 new HIV infections were diagnosed in 2010 and reported by 28 countries (no data from Austria or Liechtenstein), a rate of 5.7 per 100,000 population. The overall rate for men was 8.6 per 100,000 population and for women 2.9 per 100,000 population. The highest rates of new infections were reported by Estonia (27.8), Latvia (12.2), Belgium (11.0) and the United Kingdom (10.7). The lowest rates ( $\$ 1.0$ per 100,000 population) were reported by Romania and Slovakia.

Of the reported newly diagnosed HIV infections, $11 \%$ were aged 15-24 years. Sex between men is the predominant mode of transmission among people newly diagnosed with HIV in EU/EEA countries, accounting for $38 \%$ of the HIV diagnoses (in 2009: $35 \%$ ), followed by heterosexual contact (24\%) when diagnoses from countries with generalised HIV epidemics are excluded. The highest proportion of diagnoses reported as heterosexually acquired from persons originating from countries with generalised epidemics was observed in Belgium (66\%), United Kingdom (61\%), Sweden (60\%), Ireland (56\%) and Norway (45\%). Of all reported newly diagnosed HIV infections, $4 \%$ were reported among IDUs. The transmission mode was unknown for $18 \%$ of the diagnoses.

Some $26 \%$ of the reported newly diagnosed HIV infections were in females. The male-to female ratio was highest in Hungary (15.7:1) and Slovakia (8.3:1) and was greater than 5:1 in Slovenia, Czech Republic, Greece, Netherlands and Germany. The predominant mode of transmission in these countries was sex between men. For countries where the male-to-female ratio was less than 2:1, the main transmission mode was heterosexual contact, as reported in Sweden, Romania and Latvia.

\section{Trends in diagnosed HIV infections}

Among the $28 \mathrm{EU} / \mathrm{EEA}$ countries that have consistently reported HIV data since 2004, the number of diagnosed HIV infections has been relatively stable, from 6.5 per 100,000 population in 2004 to 5.7 per 100,000 population in 2010 . From 2004, more than 27,000 new HIV infections were diagnosed and reported each year, resulting in a cumulative total number of over 370,000 HIV infections reported since the beginning of epidemic (Figure 1). The numbers of newly diagnosed HIV infections per 100,000 population among countries reporting national data have tripled in Bulgaria and Iceland, and increased by more than $50 \%$ in the Czech Republic, Finland Hungary and Slovakia. Rates have decreased by more than $20 \%$ in Estonia, Luxembourg and Romania.

\section{FIGURE 1}

Newly diagnosed HIV infections by year of diagnosis and cumulative totals, 28 European Union and European Economic Area countries ${ }^{\mathrm{a}}$, 1984-2010

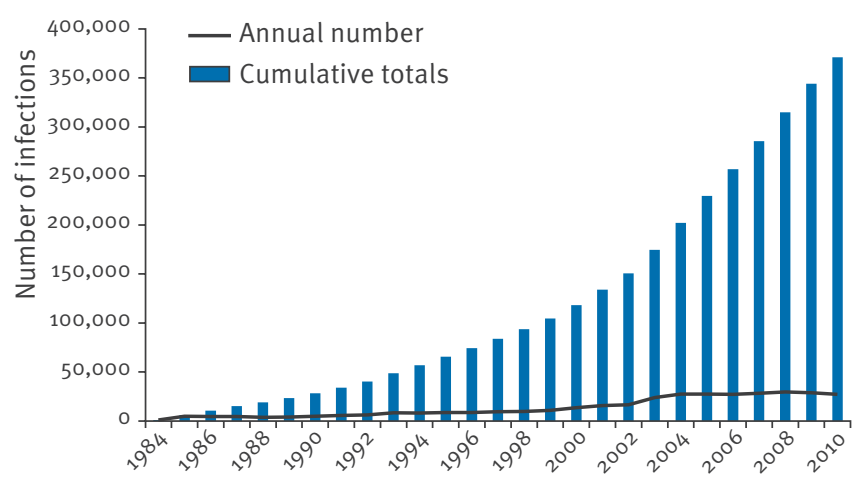

a No data from Austria and Liechtenstein. Source: [1]. 
Since 2004, 26 EU/EEA countries have consistently reported data on transmission mode (Estonia and Poland are excluded). The number of heterosexually acquired HIV infections ranged from 6,200 to 7,000 during 2004 to 2010. The number of diagnosed HIV infections acquired heterosexually and originating from countries with generalised HIV epidemics decreased by $41 \%$ during this period. The number of diagnosed HIV infections among men who have sex with men (MSM) increased by $39 \%$ and declined among IDUs by $44 \%$. The number of diagnosed HIV infections in people with unknown risk factors increased by $30 \%$ (Figure 2 ).

It should be acknowledged that for a number of countries, there are reporting delays - a time delay between diagnosis of infection and reporting of the diagnosis at national level - which limit the interpretation of trends in recent years. Such delays affect all transmission modes consistently and adjusting for it results in an increase of $4-10 \%$ for 2010 (Figure 2).

\section{AIDS diagnoses}

In 2010, a total of 4,666 cases of AIDS were diagnosed in $28 \mathrm{EU} / \mathrm{EEA}$ countries (no data from Liechtenstein or Sweden), representing a rate of 0.9 per 100,000 population. The highest rates were reported by Latvia ( 5.5 per 100,000 population), Portugal (3.3 per 100,000 population) and Spain (2.0 per 100,000 population). Among 28 EU/EEA countries reporting AIDS diagnoses consistently between 2004 and 2010, a decline was observed from 9,171 in 2004 to 4,666 in 2010. The number of AIDS diagnoses decreased in all but seven countries. An increase was reported in Czech Republic (100\% increase), Lithuania (57\%), Bulgaria (45\%), Latvia (39\%) and Hungary. Increases were also noted in Cyprus (400\%) and Malta (100\%) although reported numbers in these countries were low ( $\leq 10$ cases).

\section{Proportion of late presenters}

Late presenters are defined as patients with a $\mathrm{CD}_{4}$ cell count below 350 cells $/ \mu \mathrm{l}$ at the time of diagnosis of HIV infection. Patients diagnosed with AIDS at the same time as the diagnosis of HIV infection were not included in this analysis. Fifteen countries, where $\mathrm{CD}_{4}$ cell count was available for more than half of the newly diagnosed HIV infections, reported a total of 14,607 diagnoses ( $74 \%$ of all diagnoses) (Table). Among the 14,607 diagnoses, $49 \%$ of the patients were reported to have a CD4 cell count $<350 / \mu \mathrm{l}$.

For newly diagnosed HIV infections reported as having been acquired due to heterosexual contact, in 10 countries, more than half of these infections were in people who were late presenters, ranging from $33 \%$ in Slovakia to $63 \%$ in Netherlands. For MSM, more than half of the late presenters were reported in three countries: the proportion of late presenters ranged from $22 \%$ in Slovakia to $63 \%$ in Latvia. Among IDUs, more than half of the late presenters were reported from six countries and the proportion of late presenters ranged from $33 \%$ in the Czech Republic to $100 \%$ in Slovakia.

\section{FIGURE 2}

Newly diagnosed HIV infections by transmission mode and origin, with and without adjustment for reporting delay, 26 European Union and European Economic Area countries ${ }^{\mathrm{a}}$, 2004-2010

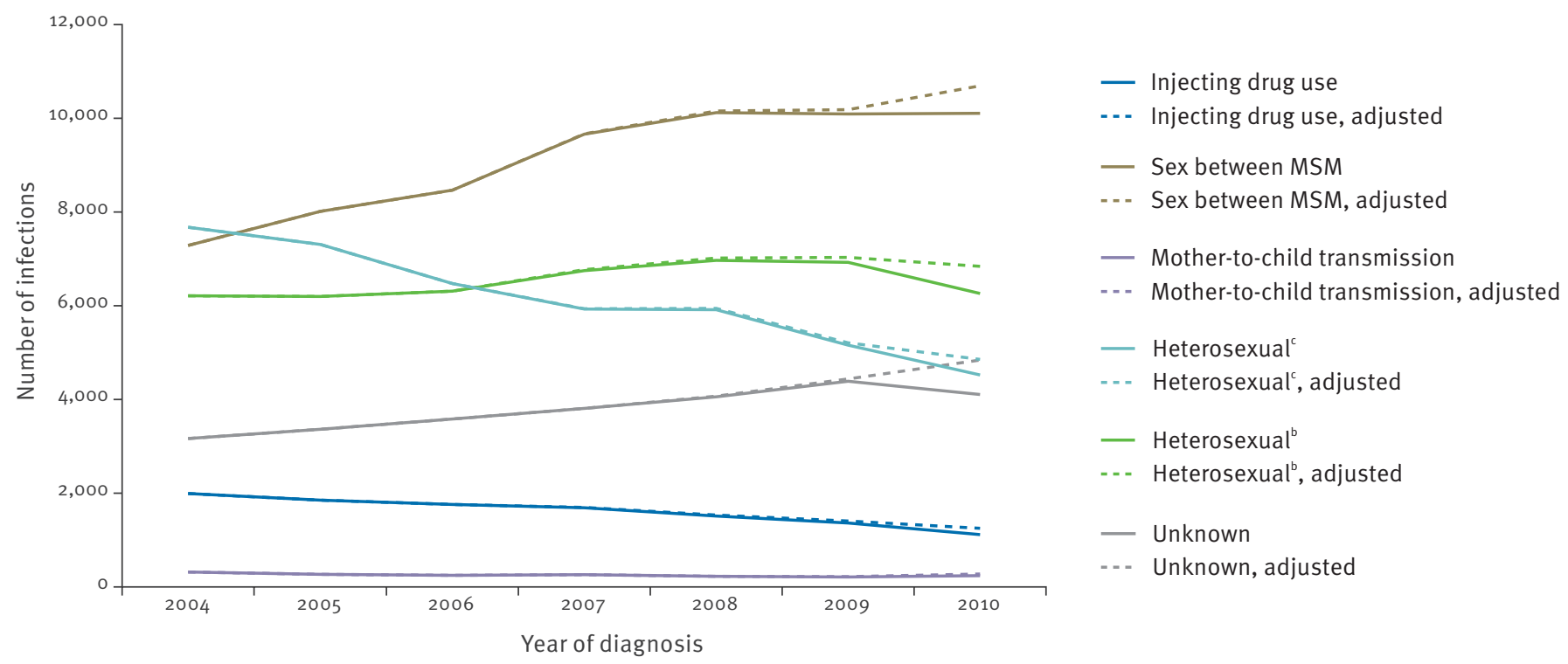

MSM: men who have sex with men.

a No data from Austria and Liechtenstein; data from Estonia and Poland excluded as unknown transmission mode in >50\% of diagnoses.

${ }^{b}$ Excludes persons originating from countries with generalised HIV epidemics.

' Includes persons originating from countries with generalised HIV epidemics.

Source: [2]. 


\section{Conclusions}

In EU/EEA countries, the highest proportion of the total number of diagnosed HIV infections continues to be reported among MSM, followed by heterosexuals. When analysing the data by reported transmission mode, the only substantial increase in the number of reported infections was in MSM. Heterosexual HIV transmission continues to be reported; although the proportion of infections attributed to heterosexual contact in persons originating from countries with generalised epidemics is decreasing, it is still high in several countries. Among IDUs, despite an apparent decline in the number of diagnosed HIV infections, a substantial number are still reported in the Baltic States, and recent and previous increases were reported in other EU Member States and neighbouring countries [3-5]. Despite the relatively low absolute numbers diagnosed due to injecting drug use, IDUs are disproportionally affected by the HIV epidemic, because of the relatively small size of the population and very rapid spread of HIV, resulting in outbreaks or rapid increases in the number of HIV infections [6]. The European Centre for Disease Prevention and Control (ECDC) has launched guidance on the prevention and control of infectious diseases among IDUs and on HIV testing and counselling in migrant populations and ethnic minorities $[7,8]$.

The number of AIDS cases is decreasing in most EU/ EEA countries except in seven Member States from eastern and central Europe. The rising numbers of AIDS diagnoses and high proportion of HIV-infected patients with low CD4 cell counts suggest a delay in HIV testing, which does not allow individuals to benefit from available treatment regimens and further contributes to HIV transmission.

There are certain limitations, which should be taken into account when interpreting these data. Reported newly diagnosed HIV infections do not represent the incidence of the infection. Newly diagnosed infections can include individuals infected recently as well as those who were infected several years ago. Reporting is influenced by several factors, such as changes in HIV surveillance system, the uptake of HIV testing, patterns of reporting, the long incubation period of the virus and slow progression of the disease. Cumulative totals presented here do not take into account death and migration patterns and therefore do not reflect prevalence. The trends presented here were partly driven by several large countries. For heterosexual transmission, diagnoses originating from countries with generalised epidemic were presented separately. This approach enables us to provide a more accurate reflection of the transmission patterns in Europe and serves as a proxy for HIV transmission occurring outside Europe. However, there is increasing evidence of HIV transmission within migrant communities [9].

TABLE

Reported numbers of newly diagnosed HIV infections ${ }^{\mathrm{a}}$ in people with known CD4 cell counts and those with CD4 cell counts $<350$ cells/ $\mu$ l, by transmission mode, 15 European Union countries, 2010

\begin{tabular}{|c|c|c|c|c|c|c|c|}
\hline \multirow{2}{*}{ Country } & \multirow{2}{*}{ 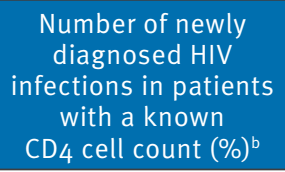 } & \multirow{2}{*}{$\begin{array}{l}\text { Number of newly } \\
\text { diagnosed HIV } \\
\text { infections in patients } \\
\text { with CD } 4 \text { cell count } \\
350 \text { cells/ } \mu \text { l (\%) }\end{array}$} & \multicolumn{5}{|c|}{$\begin{array}{l}\text { Percentage of newly diagnosed HIV infections in patients with } \\
\text { CD } 4 \text { cell count } 1350 \text { cells } / \mu \mathrm{l} \text {, by transmission mode }\end{array}$} \\
\hline & & & Heterosexual & $\begin{array}{l}\text { Injecting } \\
\text { drug use }\end{array}$ & $\begin{array}{l}\text { Sex between } \\
\text { MSM }\end{array}$ & $\begin{array}{l}\text { Mother-to-child } \\
\text { transmission }\end{array}$ & Unknown \\
\hline Belgium & $620(52.4)$ & $240(38.7)$ & 51.0 & 75.0 & 24.1 & 0.0 & 46.2 \\
\hline Bulgaria & $113(71.1)$ & $52(46.0)$ & 54.8 & 39.1 & 32.1 & NR & NR \\
\hline Cyprus & $22(53.7)$ & $10(45.5)$ & 44.4 & $\mathrm{NR}$ & 45.5 & $\mathrm{NR}$ & 0.0 \\
\hline Czech Republic & $158(87.8)$ & $40(25.3)$ & 46.7 & 33.3 & 19.2 & NR & 40 \\
\hline Denmark & $227(83.5)$ & $127(55.9)$ & 61.1 & 50.0 & 50.5 & $\mathrm{NR}$ & 57.1 \\
\hline France & $2,270(57.8)$ & $1,178(51.9)$ & 59.3 & 58.9 & 37.6 & 100.0 & 67.6 \\
\hline Italy & $2,063(71.8)$ & $1,101(53.4)$ & 57.4 & 63.7 & 45.1 & 0.0 & 54.8 \\
\hline Latvia & $157(58.1)$ & $89(56.7)$ & 50.5 & 71.4 & 62.5 & NR & 53.8 \\
\hline Luxembourg & $31(70.5)$ & $16(51.6)$ & 42.9 & NR & 58.8 & NR & $\mathrm{NR}$ \\
\hline Netherlands & $843(85.4)$ & $422(50.1)$ & 62.5 & 50.0 & 43.0 & NR & 78.9 \\
\hline Romania & $125(88.7)$ & $51(40.8)$ & 39.7 & 0.0 & 28.0 & NR & 56.7 \\
\hline Slovakia & $22(78.6)$ & $6(27.3)$ & 33.3 & 100.0 & 22.2 & NR & $\mathrm{NR}$ \\
\hline Slovenia & $33(94.3)$ & $17(51.5)$ & 71.4 & NR & 46.2 & NR & $\mathrm{NR}$ \\
\hline Spain & $2,438(84.2)$ & $1,109(45.5)$ & 55.1 & 56.8 & 36.4 & $\mathrm{NR}$ & 49.6 \\
\hline United Kingdom & $5,485(83.2)$ & $2699(49.2)$ & 59.5 & 46.1 & 38.0 & 41.9 & 52.9 \\
\hline Total & $14,607(74.4)$ & $7,157(49.0)$ & - & - & - & - & - \\
\hline
\end{tabular}

NR: no new diagnoses reported; MSM: men who have sex with men.

a In patients older than 14 years, diagnosed in 2010.

b Proportion of HIV infections with CD4 cell count reported among the total number of reported HIV infections.

Source: [2]. 
It is important to develop further HIV surveillance to better reflect the changing epidemiological situation. The inclusion of $\mathrm{CD}_{4}$ cell count at diagnosis provides an opportunity to interpret the data more in depth; however, the reporting of $\mathrm{CD}_{4}$ cell counts as well as other surveillance data needs to be improved.

Surveillance of HIV infection and AIDS in Europe is essential to describe the HIV epidemic in this region and its main characteristics. It is important to monitor the epidemic and guide the public health response in order to reduce HIV transmission. Ensuring that the data are of high quality is of utmost importance to follow up the epidemic response and international commitments [10].

\section{Acknowledgments}

We would like to thank all participating countries and national institutions of the European network for HIV/AIDS surveillance as well as colleagues at ECDC particularly Valentina Lazdina and other colleagues working on the European Surveillance System (TESSy) for their important contributions.

\section{References}

1. European Centre for Disease Prevention and Control (ECDC) World Health Organization Regional Office for Europe. 2010 HIV/AIDS surveillance in Europe. Stockholm: ECDC; 2011, Sweden. [Accessed 29 Nov 2011]. Available from: http:// staging.ecdcdmz.europa.eu/en/healthtopics/spotlight/ spotlight_aids/Documents/111130_HIV_AIDS_report_2010. pptx

2. European Centre for Disease Prevention and Control (ECDC)/ World Health Organization Regional Office for Europe. HIV/ AIDS surveillance in Europe 2010. Stockholm: ECDC; 2011. Available from: http://ecdc.europa.eu/en/publications/ Publications/111129_SUR_Annual_HIV_Report.pdf

3. Paraskevis D, Nikolopoulos G, Tsiara C, Paraskeva D, Antoniadou A, Lazanas M, et al. HIV-1 outbreak among injecting drug users in Greece, 2011: a preliminary report. Euro Surveill. 2011;16(36): $\mathrm{ii}=19962$. Available from: http://www. eurosurveillance.org/ViewArticle.aspx?Articleld=19962

4. Kivelä P, Krol A, Simola S, Vaattovaara M, Tuomola P, BrummerKorvenkontio $\mathrm{H}$, et al. HIV outbreak among injecting drug users in the Helsinki region: social and geographical pockets. Eur J Public Health. 2007;17(4):381-6.

5. Wiessing L, van de Laar MJ, Donoghoe MC, Guarita B, Klempová D, Griffiths P. HIV among injecting drug users in Europe: increasing trends in the East. Euro Surveill. 2008;13(50): pii=19067. Available from: http://www. eurosurveillance.org/ViewArticle.aspx?Articleld=19067

6. Balode D, Ferdats A, Dievberna I, Viksna L, Rozentale B, Kolupajeva T, et al. Rapid epidemic spread of HIV type 1 subtype A1 among intravenous drug users in Latvia and slower spread of subtype B among other risk groups. AIDS Res Hum Retroviruses. 2004;20(2):245-9.

7. European Centre for Disease Prevention and Control (ECDC), European Monitoring Centre for Drugs and Drug Addiction (EMCDDA). Prevention and control of infectious diseases among people who inject drugs. Stockholm: ECDC; 2011 Available from: http://www.ecdc.europa.eu/en/publications/ Publications/111012_Guidance_ECDC-EMCDDA.pdf

8. European Centre for Disease Prevention and Control (ECDC). Migrant health: HIV testing and counselling in migrant populations and ethnic minorities in EU/EEA/EFTA Member States. Stockholm: ECDC; 2011. Available from: http://www. iss.it/binary/ccoa/cont/HIV_in_migrants.pdf

9. The UK Collaborative Group for HIV and STI Surveillance. Testing times. HIV and other sexually transmitted infections in the United Kingdom: 2007. London: Health Protection Agency, Centre for Infections; November 2007. Available from: http://www.hpa.org.uk/webc/HPAwebFile/ HPAweb_C/1203496897276
10. Commission of the European Communities. Communication from the Commission to the European Parliament, the Council, the European Economic and Social Committee and the Committee of the Regions. Combating HIV/AIDS in the European Union and neighbouring countries, 2009-2013. Brussels: Commission of the European Communities; 2009. Available from: http://ec.europa.eu/health/ph threats/com/ aids/docs/com2009_en.pdf 